\title{
Model in Management Requirement and Its Impact in the Industrial Hazard (Analytical- Theoretical Study)
}

\author{
Dr. Ali Hadi Jebrin ${ }^{1}$ \\ ${ }^{1}$ Associate Professor in Production and Operation Management and Operation Research \\ Correspondence: Dr. Ali Hadi Jebrin, Associate Professor in Production and Operation Management and Operation \\ Research. E-mail: Daad_Ali@yahoo.com
}

Received: August 9, 2014

Accepted: September 30, 2014

Online Published: October 16, 2014

doi:10.5430/bmr.v4n1p17

URL: http://dx.doi.org/10.5430/bmr.v4n1p17

\begin{abstract}
The academic study of the contents of hazard management requirement in a recent interest included two directions which are insured by several studies. The first comes under the concept of accidents and torts philosophically and applicably. And the second comes under the subject of human engineering requirement. According to this direction and the concept of models to the concept of requirement management, the researchers found an interest in this study to get ready for showing the factors of integrity between same variations in human engineering, accidents and torts and its impact on industrial hazards.

The model in this study includes the relation between some activity of human engineering and accident, industrial torts, and the perception of the activity of human engineering and accident, industrial torts, and the perception of the active management in efficiency and prevents industrial hazards. Then the management is lead to achieve special organized objectives in production decisions.
\end{abstract}

Keywords: Hazard Management, Human Engineering, Accident, Industrial Torts, Industrial Hazards

\section{Introduction}

The sense of the work is always joined with risk, and risk has been joined with work for the past era, that is, since the man started to manage the wheel of products, and the risk will remain until it is controlled to the minimum level, by creating a healthy and safe environment for work and trying to find preventive plants which includes human engineering.

Several writes and researchers have presented the role of human engineering and accident in the process of making organizational decision, and dealing with risk.

Theorists confirmed this relation in the field of theoretic decision, and that was embodied clearly in the theory of benefit.

Through the theoretical review and the models shown in this purpose many questions may raise about the range of:

1.1 There is a relation between the requirement of the human engineering and accident, and the manager's perception about the management requirement.

\subsection{The effect of the managerial structure in the process of making organizational effective decisions.}

According to this we may formulate a model suggested for this study that may be depended upon as a guide for the discussion of the subject of risk, and the way of managing it.

This model (Fig.1) includes the relation between some activity of human engineering and accident, industrial torts, and the perception of the activity of human engineering and accident, industrial torts, and the perception of the active management in efficiency and prevents industrial hazards. Then the management is lead to achieve special organized objectives in production decisions. 


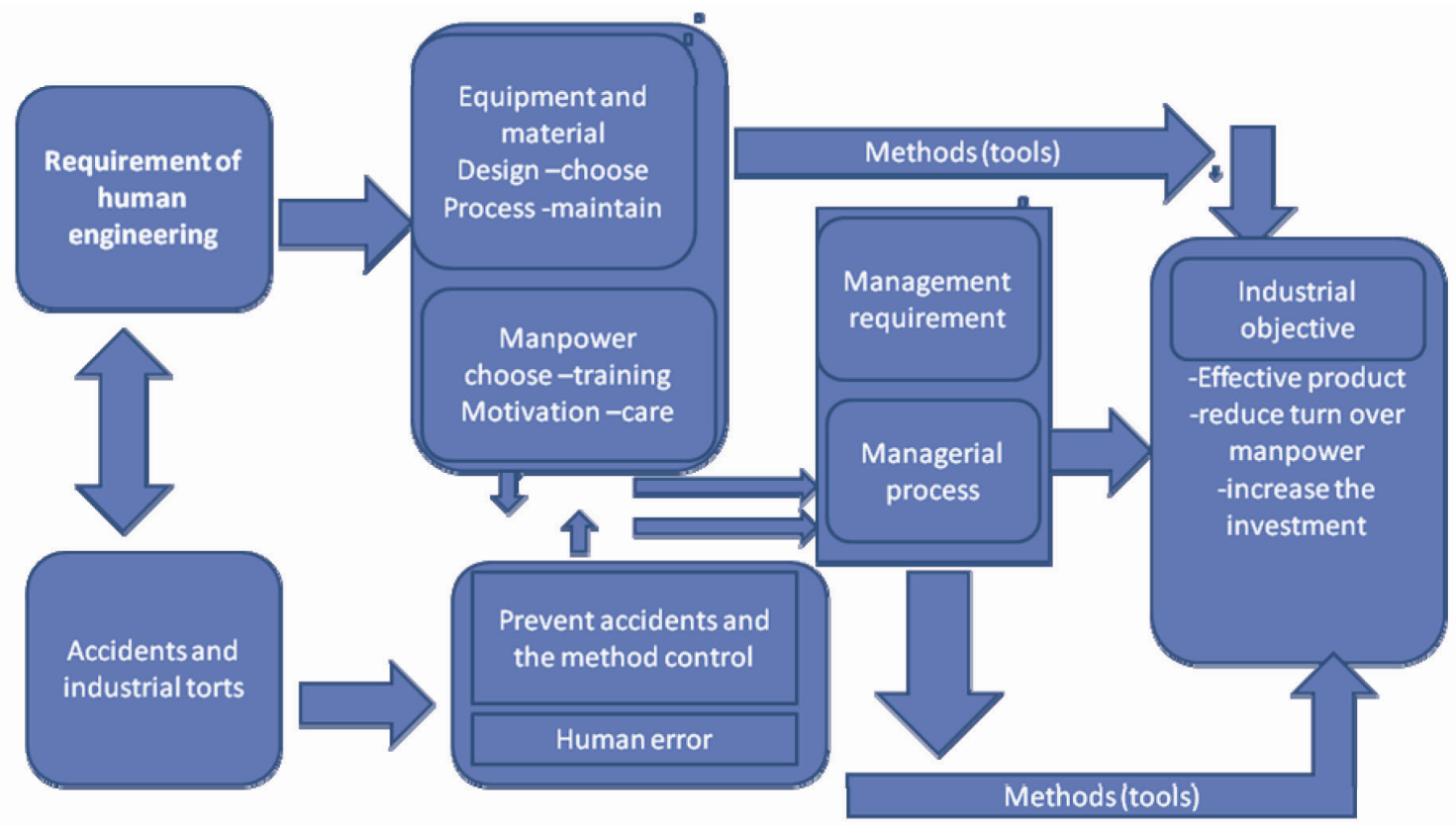

Figure 1. Suggested study model: the management requirement and its impact on industrial hazards

This determination of variation depends on the level of perception of managers in general and managers of hazard on specific, for the importance of these variations that build a vital effect in achieving organized objectives. We may explain the movement of the model in this study by some major assumptions:

$A$. There is a relationship that joins human engineering and hazard management in order to achieve production objectives.

$B$. There is a relation that joins the accident and the torts in work, and the hazard management in order to achieve effective production objectives.

$C$. The requirement of the human engineering is effectively joined with the accident by putting efficient management to achieve high production objectives.

The assumption and model will be supported through the theoretic review of the mental sight for the research variation, and will also be assisted by the research and studies concerning that.

\section{Literature Review}

The paucity of studies in this field goes back to the recent launch such a model in management requirement and its impact in the industrial hazard. Therefore, the researcher tried hard to research and know-how for the purpose of correcting some of the studies related to the direct or indirect that found three studies which follows:

2.1 Entitled information for preventing accidents for the Public Sector at Asian Productivity Organization, this study focus on effect of accident problems, management information system (MIS) strategy, and organization culture (Study Dillon, Jane, 2001).

This publication contains the results of extensive research on and analyses of public-sector organizations in APO members conducted by a team of MIS experts from Japan, the republic of Korea, Malaysia, the Philippines, Singapore, Thailand, and the U.K. The team examined why MIS is important in the public sector, and then explained the basic concepts in the context of the APO MIS framework. Most importantly, they included five detailed case studies showing how MIS is being applied in public-sector organizations in APO member countries to improve their productivity and offer better services and solutions to citizens. 
2.2 Entitled The contribution of Evaluation to human and engineering of Tacit productivity, this study focus on effect of Human and engineering on organizational Manufacturing by evaluation In World bank (Study Skinner, W, 1992) (The Case of the World Bank).

The researcher concluded that the experience accumulated by development agencies throughout the world has become a source of organizational knowledge, which, according to human error is transferred through processes of human and engineering.

Based upon three case studies and in-depth interviewing of World Bank managers and evaluators over two years, this article explores the contribution of evaluation to organizational manufacturing. The study analyses the use patterns of evaluation as a source of knowledge within the World Bank.

2.3 Entitled Expanding the material and manpower: managing enabling contexts in risk management, this study focus on effect industrial hazard (material, manpower) on industrial hazard (Study Heinz, W., 1989).

The researcher investigate and analyze the concept hazard in the fields of information science, management/business and information systems literature in order to understand its conceptual evolution, discussions, applications and expansion since its introduction in 1988.

\section{Requirement Management in the Industrial Hazard}

The requirement management is confirmed on a group which is based on a group of major principles:

3.1 Incorrect works, inconvenient environment, unsafe circumstances and accidents are considered as signs which clarify any errors presented in management system (Rosebush, 1989: 45).

3.2 It is always possible to forecast strong savagery and cruelty of the torts that are caused by the environmental circumstances and then it would be possible to define and control such circumstances.

3.3 The management must be managed like any other job in the enterprise.

3.4 The job of the management is to determine and define the errors of work, design maintenance and the way of motivating manpower, which could lead to accidents and torts. This job may be executed in three ways:

A. Question: why do accidents and torts happen and what are their major causes?

B. Question: why should we be interested in human engineering?

C. Question: is it used actively, safely and in preventive and controlled ways?

The diagram (Fig.2) shows the functional jobs of requirement management and its succession represents its basic managerial job as shown in the model of the study.

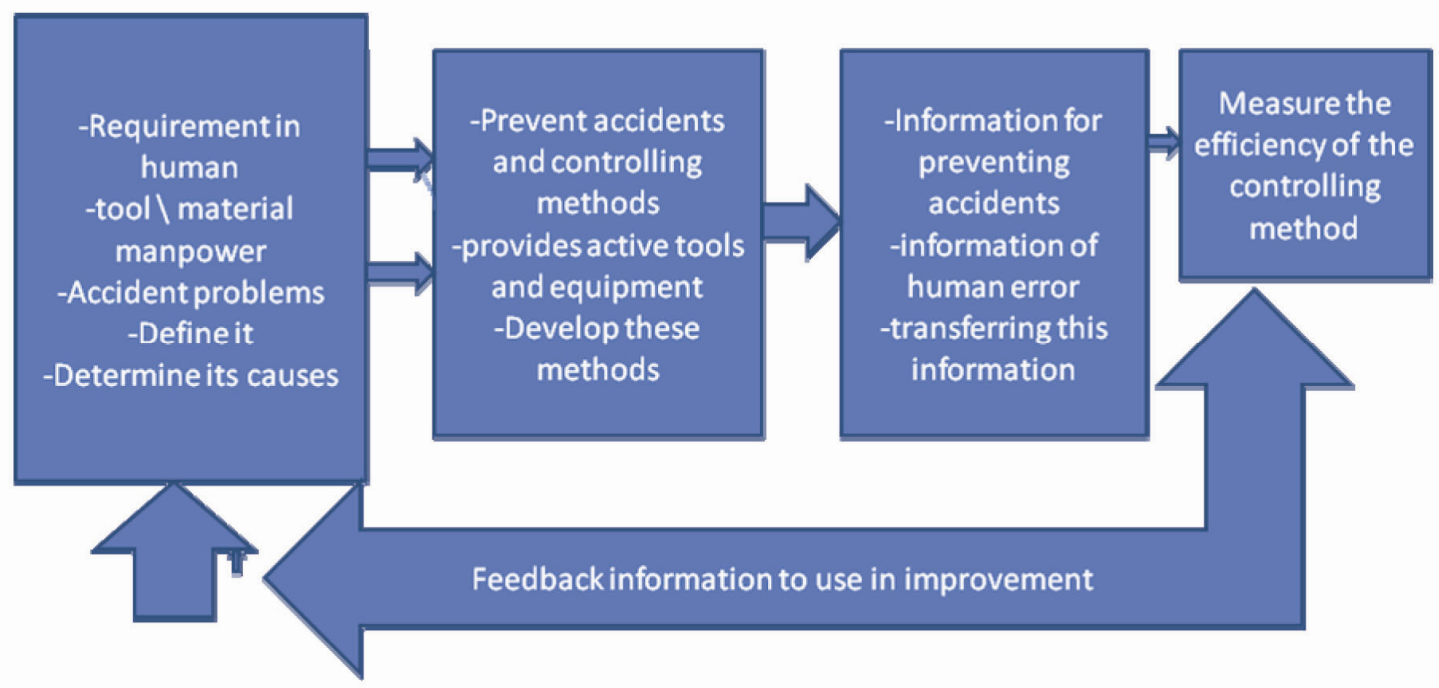

Figure 2. Shows the job function of requirement management and its succession 


\section{The Direction of Management Hazard Requirement and its Impact on Industrial Hazard}

The interest if the hazard manager has been increased in the direction of changing their management system, because they want to achieve minimum loss. It is clear that most hazard managers in the world consider management as a method to face problems of production and a direction to gain more profitability (Thieranf, 2006: 98).

Naturally, we need an active production but we want to achieve it in a way that there will be no torts. What we want is management with the production, and we do not want production with the management. In order words, we want safe and secure production (Singleton, 2013: 6).

In order to insure this, the top managers insure that is a relation between the management and the production, and this interest has been imbedded by academic studies of the management requirement among the recent interest which includes two directions that insures it several studies (Riegel, 2014: 675).

4.1 Dealing with the subject of human engineering requirement consists of taking care of tools, equipment, manpower, fitness, and the arrangement between them.

\subsection{Its contents lie under the concept of accident and torts.}

Philosophically and applicably, there are several known tools and systems related through which the integrity of requirement production is reached, and here exists the job of requirement management and how it reached the integrity between the two directions and its impact on industrial hazards (Riegel ,et.al :2014).

The author shows that the subject of integrity has faced approval of researchers, although integrity still phases, especially in the field of hazard management through:

A. The study of integrity between human engineering, accidents and torts focuses on the possibility of knowing the factors of hazard management which requires studying and application.

B. Integrity Limits the factors and the limitations that have an impact on several industrial companies in the range of building its strategy in hazard management and showing the relation of the force and effect between these factors and dimensions which consolidate the third assumption, which are suggested in this study, meaning "The requirement of human engineering is joined effectively with the accident by putting efficient management to achieve high production objectives".

The researchers found through these two directions of principles of vocabulary words, an interest in this study to stand in line of the project that is most important to prepare for showing the factors of integrity between the same variations in human engineering, and the variations of accident in the frame of management requirement aspects and its impact on industrial hazard (Green, 2009).

It is worthy to point out here that the researcher's interest in theoretical framing of the management requirement concepts which aims to formulate an approach which could be worthy to fit through the integration between the two directions mentioned above. In addition, applying it to fit in different business companies taking into consideration the new subjective and personal task.

\section{Accident, Torts the Tools of preventing it and its Impact on industrial hazard}

\subsection{The concept and the importance}

The problems of accidents and torts in the industrial and service organizations and others concerned are one of the most basic problems in all levels in the world, especially the level of industrial, health and vocational security. Thus accident and torts increased in a great proportion as a result of great industrial growth in the world, and the use of complex technology which needs high efficiency and skill. To deal with this problem, this has a great negative sign on the economy because these accidents and torts lead to a huge destruction in raw materials, production, tools, machinery and most importantly human power which is considered the major tool for production. Therefore it is necessary to study the problem of modern scientific study and put the correct system which deals with this problem to increase its effects on the society. thus, the torts are caused by accidents at work, it's great injuries, functions and what adds to mental and psychological injuries that are caused by it.

Accidents occur without planning causing physical, mental or functional harm, Therefore accident are more general than torts.

The cost of accident and torts in all types of industries and business remains high in an unacceptable manner where its costs we can measure in two ways; the first is the financial measure and the second is the human measure. 
There is a censor in Great Britain which points to death caused by business and torts disease that happens to employees much more than the absences which are caused by torts and the variation in work.

The censor shows that the number of accident happening at work in some countries like Japan and The USA are more than one million torts each year and in other countries like France, Germany and Italy is more than a million (Anthony, 2009: 90).

From this we understand that work accidents lead to two essential losses; one in its narrow concept meaning the individual either him/herself or his/her private income, and the other with its broad concept meaning the loss that effects the society as a result of many accidents.

Accidents and torts, according to many studies, (88\%) of the total accidents and torts happen because of human error because of the importance of this subject we show its concepts and application (Rosabeth, 1989: 34).

\subsection{Human Error}

We are all exposed to error, and the improvement of technology increased the probability of human error. About 2/3 of danger is caused by human error, such as, flight, chemical and factory accidents (Mccormick, 2006: 344). The use of the computer does not prevent human error as well, because people did not only interfere in the working operation but also in designing manufacturing, checking and maintaining. even if a great proportion of working operations are achieved automatically, there still remains the possibility of human error it is worthy to point out that the organization of prevention insists on having a human as the designer of the designer of the system .therefore, we do not expect that person to know everything, and as several writers agreed that it is impossible to remove human error in the fault design of the tool.

Thus error means fault in completing jobs according to limitations, specifications, outcomes and time. The study insures that most causes for disasters are the human fault.

The philosophy of designing a system to fit with the ability of employees is the new scheme and the psychological factors like elevating the moral spirit, decreasing the strength needed and increasing estimations all play a role limiting accidents and torts (King, 2001: 78).

Several studies in the use as well as in the world health organization oblige several enterprises in having effective written information for safety, which should include safety precautions, training, moral spirit and strength enhancers.

We may say that error is a fact that we cannot avoid which is a result of a position or condition of the individual in society like falling from high places or committing mistakes, which may lead the individual to feelings of guilt and blaming him \herself (Banister \& Bawcutt, 2011).

Such thinking leads us to be convinced that error exists and sometimes it is not possible to avoid .error exists when we are not able of achieving our objectives.

Thus error is a part of human behavior. And according to that we may limit a general strategy to study the decrease of human error as follows:

$A$. limits a certain study through which limits the samples and results of the system in which error occur (Human Error).

$B$. Analyze the type of error which appears in the system and defines the best method according to its counted errors .it is also preferable to use the quantitative method to achieve this goal as a scientific method to limit human error.

The causes of human error are usage, data processing, skill and expertise, main wondering and many other factors.

We conclude from the above assumptions that most accidents and torts are caused due the fault of neglecting the human recourse at the time of doing his/her job and these factors with unsafe conditions may increase causing accidents, torts and human errors done by the designer of the work or the contractor of building or the machine designer and everyone concerned, building, setup, management, workers and so on.

This insures the relation between accidents and torts in working and hazard management when wanting to achieve high production, which consolidates the creativeness of the second major assumption meaning, "there is a relation that joins between accidents and torts in work and hazard management in order to achieve effective production objectives". 


\subsection{Planning (Fig.3) for torts and accidents}

We see from this figure (Fig.3) that there are two reasons for causing torts:

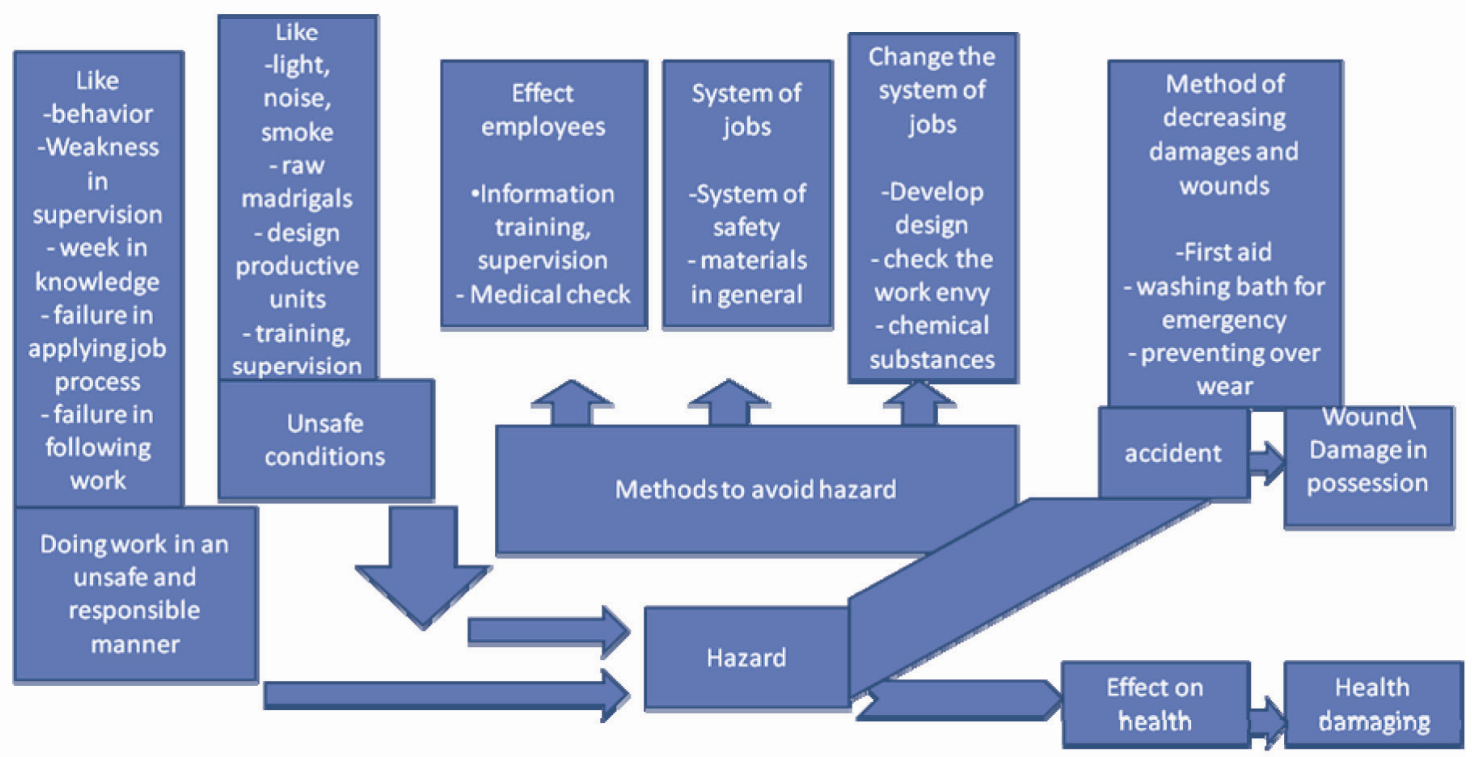

Figure. 3 for Hazard Accidents

First: the unsafe conditions of jobs which have many causes, as shown in (Fig.3).

Second: irresponsibility and doing the work in an unsafe manner (Rosabeth, 1989: 25).

Which has sub-causes as shown in (Fig.3).there are also many examples and methods to avoid hazard. Through (Fig.3) we can see that hazard may lead to accidents which are either of direct torts of work that causes hazards or from harmful imposition but without human torts. We can also see from (Fig.3) the method of avoiding risk.

We conclude from what has been mentined that the structure of management requirement depends upon tools, methods and what has been shown in the model of the study to avoid accidents and torts, which are one of the principles in the process of managing of management requirement.

\section{Human Engineering and its Impact on Industrial Hazard}

\subsection{Definition and importance}

Human engineering is defined as an anatomy, physiology and psychology study of man in a working environment (Don, 2003).

While engineering relations mean consistency and coincidence between the size of the human body and his muscular susceptibility power and what he uses from machines and tools as a target of adapting his environment according to his body size and power as an integrity productive unit. the human engineering originates from the study of engineering and experimental psychology which includes a great deal of industrial psychology.

The purpose of coordinating between then psychology scientist and engineer was an attempt to limit errors in which engineering fails to decrease accidents and risk. Although web can decrease human risk by correct human engineering, but this ratio will not become (Hiddie, 1999: 36).

Production engineering care in any enterprise includes measured dimensions of machines and tools and the range of its efficiency in production (Grandjean. E., 2003), as an integrity unit by itself. We should also concentrate on improving physical work conditions such as; lighting, ventilation, heat, noise and industrial safety.

In conclusion, we found that the interest is focusing on conveniently adapting man to the working place and its surroundings. the recent intention of production engineering is guiding the designer of the working place and the specialist of human engineering towards adapting to the working place and all its surrounding and making it convenient to man's body measurement, his muscular ability and susceptibility strength to supply a maximum amount of physical and mental comfort, achieving high productive goals, decreasing the circulation of work and increasing investments which achieves an internal relation between the essential variations. For example, tools, 
materials and man power are the most important requirements of human engineering as shown in the model of this study.

6.2 Why is human engineering required?

6. 2.1 Anything used by individuals must be designed in relation with the individual.

6. 2.2 The most major accident is caused by human error.

6. 2.3 Saving time and movement.

6. 2.4 Designing machines and tools and adapting them to be useful to the individual requirement.

This consolidates the necessary availability of convenient methods to achieve high productive goals. All this is shown in the model of the study.

6.3 The system of man-machine

At the time of designing any machine or tool used by man the principle of the man and the machine as being the integral productive unit should be considered, that is the principle of uniting man and machine. However, the role of man does not depend on the requirement of systems as such, but on the limits of manpower and his ability to do such requirements. And if we meditate on what man did from the time he/she received the information or guidance till he/she did their job, we find that he/she receives the information first and then does the job of decision making. Thus, the work he decides to do mean that he is making the effort of thinking and it is difficult to decide on what is exactly happening inside his head, but it is known what happens to the information that goes through his central nervous system.

There are several studies that deal with the perception process of mangers and their achieving of goals especially in the field of war. Also the employee receives a lot of excitement from the environment that surrounds him and through his senses of hearing, seeing, touching, tasting and smelling, especially the excitement that he receives from his working environment or from the equipment which he/she works with.

From this we conclude that the difference between man's and machine is caused by mans flexibility in decision making or changing of decisions by the differences of psychological cases and the impact of that on his decisions.

The conclusion of this study is consolidated through the concept of the relation of human engineering in the managerial structure in the process of organized decision making and approving the right of the first major assumption that comes up, "there is a relation that joins some human engineering and hazard management in order to achieve the production objective," and explaining the creativeness of focusing on this model of study.

\section{Conclusion}

7.1 The academic study of the contents of hazard management requirement in a recent interest included two directions which are insured by several studies.

The first comes under the concept of accidents and torts philosophically and applicably. And the second comes under the subject of human engineering requirement. According to this direction and the concept of models to the concept of requirement management, the researchers found an interest in this study to get ready for showing the factors of integrity between same variations in human engineering, accidents and torts and its impact on industrial hazards.

7.2 The study insists on the necessity of concentrating on some requirements of human engineering and the method used as a base to limit the industrial hazard.

7.3 The operation of determining the factors of accidents and torts is one of the responsibilities of the tope management, which must be raised from the activities in the operations strategy to the hazard manager in an industrial company. And this explains the existence of exchanging operations which lead to the requirement of hazard management.

7.4 The result of managerial studies and hazard management lead to the creativeness and acceptability of the major assumption in accordance to the philosophical principles of the requirement hazard management.

7.5 We can consolidate the conclusion above through the creativeness of the model study. Thus, through it we reach the concept, variations, factors and the impact of each of these on the industrial hazard. Therefore, this study contributes by giving an analytical-theoretical frame to the decision making process to build efficient hazard management. 


\section{References}

Anthony G. (1987). Manufacturing Engineering: Economics and Processes. Englewood Cliffs, New Jersey, Applied Ergonomics. http://dx.org/10,2307/i556363

Banister, T. E \& Bawcutt, P.A. (2011). Practical Risk Management,_, ${ }^{\text {st }}$ Edition, Prentice-Hall Inc., Englewood cliffs.

Dillon, Jane. (2001). The Role of Ergonomics in the Development of Tests for Furniture.

Don, Hoernschemeyer. (2003). Creating Conditions for Excellence. Manufacturing System, (Dec.). http://dx.doi.org/10.1009/10551-007-9609

Grandjean, E, Fitting. (2003). The Task to the Man. An Agronomical Approach, Tylor and Francis ltd.

Green, Mark. (2009). Risk insurance ${ }_{2}$ South-Western Publishing Co. Cincinnati. Prentice Hall Inc. Englewood, New Jersey.

Heinz, Williams. (1989). Risk Management and Insurance. McGraw-Hill Inc. America.

Hiddie, Adams, n.l. (1999). Obtaining Ergonomics Information about Industrial Injuries, A five year Analysis Ergonomics, June.

King, John R. (2001). The Management of Engineering Production. Englewood Cliffs.

Mccormick, Ernest, t. t, joseph. (2006). Industrial Psychology. Prentice-Hall Inc. Englewood, New Jersey.

Riegel, Robert, Miller. (2014). Insurance Principles and Practices, prentice-Hall Inc, Englewood cliffs.

Rosabeth, Moss, Kanter. (1989). Power Failure In Management Circuits. Harvard Business Review. (July - Aug).

Singleton, W. T. (2013). Techniques for Determining the Causes of Error. Applied Ergonomics, sep.vol .27.No.4.

Skinner, W., Manufacturing. (1992). The Formidable Competitive Weapon. Administrative Science Quarterly, Vol . 37. No . 1. (March).

Thieranf, R. C. \& Gelding D. W. (2006). Management Principles And Practices: Acontingency And Questionnaire Approach (John Wiley and Sons). 